\title{
A novel surgery: robotic transanal rectal mucosal harvest
}

\author{
K. N. Howard ${ }^{1}$ - L. C. Zhao ${ }^{2}$ A. C. Weinberg ${ }^{2} \cdot$ M. Granieri' ${ }^{2}$ M. A. Bernstein ${ }^{3} \cdot$ A. L. Grucela ${ }^{3}$
}

Received: 27 January 2019 / Accepted: 13 May 2019 / Published online: 29 May 2019

(c) Springer Nature Switzerland AG 2019

Buccal mucosal grafts (BMG) are traditionally used in urethral reconstruction [1]. There may be insufficient BMG for applications requiring large grafts, such as urethral stricture after gender-affirming phalloplasty. If rectal mucosa is used, there is less postoperative pain, no oral impairment, and grafts can be larger [2,3]. Laparoscopic transanal minimally invasive surgery (TAMIS) has been described for many applications [4]. Due to technical challenges of harvesting a sizable graft within the lumen, we adopted a new robotic approach, which has been shown to be safe and feasible. To our knowledge, this is the first use of robotic TAMIS (R-TAMIS) for rectal mucosa harvest.

This procedure is performed in the lithotomy position with a $30^{\circ}$ scope, two instrumented robotic arms, and an assistant port. Key features of the technique include: (1) consistent insufflation of the rectum and colon to $12-15 \mathrm{mmHg}$ to avoid luminal collapse; (2) distal-to-proximal measurement of the desired length of mucosa and scoring of the area prior to dissection; (3) interval injection of lidocaine with epinephrine solution to raise and hydrodissect the mucosal plane and minimize bleeding; (4) dissection to submucosal plane and elevation of the flap with gentle blunt dissection and cautery; (5) retraction of the flap by suture placement for unobstructed view; (6) resulting mucosal defect left to heal by secondary intent to avoid stricture; and (7)

Electronic supplementary material The online version of this article (https://doi.org/10.1007/s10151-019-02008-8) contains supplementary material, which is available to authorized users.

A. L. Grucela

Alexis.Grucela@nyulangone.org

1 New York University School of Medicine, New York, NY, USA

2 Department of Urology, New York University Langone Medical Center, New York, NY, USA

3 Department of Surgery, Division of Colorectal Surgery, New York University Langone Medical Center, 530 1st Ave. Suite 7V, New York, NY 10016, USA post-surgical sigmoidoscopy to inspect for injury and complete hemostasis.

The attached video demonstrates our technique of R-TAMIS in the harvest of rectal mucosa. None of the six patients on whom we have performed this procedure have had intra- or postoperative rectal complications. In all cases, graft size and quality were sufficient for the intended subsequent onlay graft urethroplasty.

\section{Compliance with ethical standards}

Conflict of interest The authors declare that they have no conflict of interest.

Ethical approval All procedures performed in the study involving human participants were in accordance with the ethical standards of the Trust and with the 1964 Helsinki declaration and its later amendments or comparable ethical standards.

Informed consent Written informed consent was obtained from all patients for publication of the accompanying images.

\section{References}

1. Lumen N, Oosterlinck W, Hoebeke P (2012) Urethral reconstruction using buccal mucosa or penile skin grafts: systematic review and meta-analysis. Urol Int 89(4):387-394

2. Browne BM, Vanni AJ (2017) Use of alternative techniques and grafts in urethroplasty. Urol Clin North Am 44(1):127-140

3. Palmer DA et al (2016) Urethral reconstruction with rectal mucosa graft onlay: a novel, minimally invasive technique. J Urol 196(3):782-786

4. Martin-Perez B et al (2014) A systematic review of transanal minimally invasive surgery (TAMIS) from 2010 to 2013. Tech Coloproctol 18(9):775-788

Publisher's Note Springer Nature remains neutral with regard to jurisdictional claims in published maps and institutional affiliations. 